\title{
Professores na educaÇÃo de jovens E ADULTOS: INSERÇÃO, PRECARIZAÇÃO E FORMAÇÃO CONTINUADA
}

\author{
THE TEACHING IN THE YOUTH AND ADULTS EDUCATION, \\ BETWEEN PRECARIZATION AND THE CHALLENGES OF \\ CONTINUING EDUCATION
}

\author{
Joana Celia Passos \\ Doutora em Educação pela Universidade Federal de Santa Catarina. \\ Docente da Universidade Federal de Santa Catarina. \\ Santa Catarina. SC - Brasil \\ passos.jc@gmail.com
}

\begin{abstract}
Resumo: O presente texto apresenta reflexōes sobre a formação continuada ofertada aos professores que atuam na Educaçấo de Jovens e Adultos em uma Rede Municipal de Ensino, explorando suas interfaces com os processos de ingresso e de constituição da docência nessa modalidade educativa. Análise documental e entrevistas foram os procedimentos metodológicos utilizados para compreensão do objeto. Como resultados principais, evidenciou-se a desvantagem apresentada da EJA no conjunto das políticas educacionais, dado que a concepçáo de provisoriedade dos gestores públicos não os permite assumir a educação como direito para jovens e adultos, o que reflete na baixa institucionalizaçấo dessa modalidade nos sistemas de ensino.
\end{abstract}

Palavras-chaves: Docência. Educação de Jovens e Adultos. Formação continuada.

ABSTRACT: This paper presents reflections on the continuing education offered to professionals working in Youth and Adults Education and its interface with the process of entry and the constitution of teaching of the teachers in this educational modality, in a Municipal Education Network located in Southern Brazil. Document analysis and interviews were the methodological procedures used to understand the object. Became evident the disadvantage which Youth and Adults Education has in the set of educational policies. The concept of temporariness from the public officials about this educational modality, doesn't allow them to take education as a right for youth and adults, demonstrating the low institutionalization in basic education systems.

KeYwORDs: Teaching. Youth and Adults Education. Continuing Education. 


\section{Introdução}

Ao examinar as políticas públicas para formação continuada, Gatti (2008) identifica distintas práticas que, por vezes, se referem a cursos ofertados após a graduação ou após o ingresso na profissão docente; por outras, se referem a toda atividade que propicie reflexão, informação, discussão e trocas e que favoreçam o aprimoramento profissional, como

horas de trabalho coletivo na escola, reuniôes pedagógicas, trocas cotidianas com os pares, participação na gestão escolar, congressos, seminários, cursos de diversas naturezas e formatos, oferecidos pelas Secretarias de Educação ou outras instituiçôes para pessoal em exercício nos sistemas de ensino, relaçóes profissionais virtuais, processos diversos a distância (vídeo ou teleconferências, cursos via internet etc.), grupos de sensibilização profissional, [...] (GATTI, 2008, p. 57) 
aqui apresentados foram obtidos em pesquisa mais ampla, realizada entre 2009 e 2010. Foram analisados documentos normativos nacionais, estaduais e municipais sobre a docência e entrevistados dezesseis profissionais da modalidade educativa, entre professores, coordenadores pedagógicos e gestores públicos que atuavam na referida rede de ensino no ano de 2009. A interlocução com a produção acadêmica sobre formação continuada de professores e, em especial, a formação continuada de professores para e na EJA foi fundamental para o exame que aqui se realiza.

\section{A inserçáo profissional para a docência na EJA}

Os profissionais da educação de pessoas jovens e adultas da RME aqui analisada desfrutam de baixo reconhecimento social da profissão. Marin (2010) considera que a precarização do trabalho docente se caracteriza tanto pelos aspectos referentes às más condiçóes de formação quanto às condiçôes de trabalho. Por sua vez, Pereira-Diniz (2010) alerta que é preciso levar em conta a indissociabilidade entre a formação e as condiçôes adequadas para a realização do trabalho docente, pois, do contrário, corre-se o risco de culpabilizar os professores pelas mazelas do sistema educacional brasileiro ou considerá-los exclusivamente vítimas do processo de reestruturação produtiva e das políticas neoliberais.

No ano de 2009, os professores que atuavam na EJA na RME eram, em sua maioria, substitutos e contratados anualmente por meio de processo seletivo para atuação por prazo determinado. Em toda a sua história, o município realizou uma única vez concurso público específico para EJA, no ano de 1994, e em 2007 incluiu um processo seletivo específico para professores de educação de jovens e adultos. No momento de realização da pesquisa, atuavam cento e quarenta e seis profissionais, considerando professores, coordenadores de núcleos, auxiliares de coordenação e equipe da Secretaria Municipal. Desse conjunto, treze efetivos por concurso público no Ensino Fundamental. Do total de cento e dois professores, setenta e três eram mulheres e 29 homens. Quanto à faixa etária, percebe-se o predomínio de professores até quarenta anos. No quesito formaçáo, um possuía pós-graduação em nível de doutorado; dezessete, em nível de mestrado e vinte e três, em nível de especialização; cinquenta e sete possuíam licencia- 
tura completa, e apenas quatro cursavam alguma licenciatura. Nenhum possuía formaçáo inicial em EJA.

As informaçóes acima indicam a existência de um quadro docente qualificado academicamente e distante de caracterizar a precarização indicada por Marin (2010), principalmente se considerarmos que a EJA não tem sido uma modalidade educativa de grande prestígio para requerer profissionais com maior formação. No entanto, cabe a pergunta: essa formação acadêmica tem possibilitado que os professores desenvolvam uma prática pedagógica que assegure os princípios e especificidades dessa modalidade?

Constatou-se também a existência de núcleos de EJA constituídos por professores que estavam pela primeira vez atuando na modalidade. Nesses núcleos, a presença de professores iniciantes, contratados como temporários, variava entre $75 \%$ e $100 \%$. Havia núcleos em que, no ano pesquisado, todos os professores eram substitutos, inclusive o coordenador, o que sugere, entre outros fatores, que a docência na EJA também tem sido utilizada para complementação de carga horária no período noturno, contribuindo com a ideia de provisoriedade.

$\mathrm{O}$ relato de uma coordenadora informa que o reduzido número de professores efetivos tem comprometido o trabalho na EJA:

Eu acredito que se a gente tivesse um corpo efetivo na EJA o trabalho seria muito melhor. A sensação que eu tenho a cada ano é que a gente está sempre começando. [...] Até que as pessoas tomem pé da proposta, que é tudo diferente daquilo que a pessoa já viu na formação ou estudou, já é final de ano. Quando começa a engrenar é final de ano e no próximo ano você não sabe se ele volta. Eu acho muito complicado lidar com isso. (Coordenadora $\mathrm{M})^{1}$.

A contratação de professores substitutos para a EJA na RME estabelece como critérios para inscrição: que o profissional tenha graduação completa ou seja estudante da $5^{\text {a }}$ fase de licenciatura; para alfabetizador é necessário ter formaçáo no ensino médio em magistério, com habilitaçáo em anos iniciais do Ensino Fundamental, ou curso de licenciatura em Pedagogia, com habilitação para essa etapa; ou, ainda, normal superior, 
com habilitação em anos iniciais do Ensino Fundamental. Não integra o perfil desejado dos profissionais a experiência e/ou a formação em educação de pessoas jovens e adultas.

O processo seletivo consiste em duas etapas: prova escrita e prova de títulos. As questóes da prova escrita versam sobre conhecimentos gerais de temas relacionados à educação e conhecimentos específicos sobre temas relacionados ao cargo, área ou disciplina ${ }^{2}$ para a qual o candidato se inscreveu, ainda que, nesta RME, a proposta curricular da educaçáo de pessoas jovens e adultas não esteja organizada por área de ensino ou disciplina. A prova escrita tem também como referência os conteúdos relacionados às identidades que configuram o sujeito da educação de pessoas jovens e adultas; o conhecimento na perspectiva do pensamento complexo; a história da EJA; as diretrizes curriculares nacionais e demais legislação da EJA; o Estatuto da Criança e do Adolescente (ECA); a política nacional, estadual e municipal do idoso; a pesquisa como princípio educativo; o trabalho docente na EJA; a avaliação; as concepçôes de letramento e alfabetização de adultos.

Embora para pontuação no processo seletivo o tempo de atuação em docência na EJA não seja computado, observa-se que a maioria dos conhecimentos exigidos dos professores correspondia às especificidades da educação de pessoas jovens e adultas, demonstrando uma tentativa de focalização da área. Vale lembrar que os conhecimentos exigidos pelo edital, na maioria das vezes, não compóem o currículo dos cursos de formaçáo inicial $^{3}$ e a ausência deles têm comprometido a prática pedagógica dos professores, como informam os estudos de Machado (2010), Soares (2008) e Di Pierro (2005), entre outros.

Aliada à forma de contratação, a condição salarial dos professores também expõe a condição desigual do trabalho dos profissionais da EJA na RME, como explicita uma professora: "Nós não temos direito a 40 horas na EJA, mas o efetivo tem.” (Professora W.) A dimensão salarial recrudesce a precarização do trabalho do professor contratado em caráter temporário.

Uma estratégia utilizada pela RME para assegurar professores efetivos na EJA tem sido o concurso de remoção, que consiste na disponibilidade, pelo poder público, de vagas (por área curricular) para que professores já efetivos possam assumi-las. Como critérios de pontuação são considerados o tempo de serviço e a formação, e com isso têm mais chance de remoção os que estão há mais tempo na RME. 
A constituição de equipes permanentes de educadores nas redes de ensino tem sido um dos principais desafios indicados pelos seminários nacionais sobre formação do educador de jovens e adultos:

A existência, por si só, dos educadores que atuam na EJA náo é suficiente. Há de se constituir um coletivo de educadores de jovens e adultos permanente/orgânico, buscando a efetividade desse profissional na rede, substituindo educadores com contratos temporários. É necessário repensar critérios de remoção desses profissionais (remanejamento/distribuição de aulas), tomando por referência a formação e a experiência em EJA, enfrentando inclusive as questôes corporativas que têm dificultado a compreensão da especificidade do trabalho dos educadores de jovens e adultos. Por fim, os gestores de sistemas destacam a necessidade de valorização dos educadores da EJA, inclusive com salário equiparado às demais modalidades. (SEMINÁRIO NACIONAL DE FORMAÇÃO DE EDUCADORES DE JOVENS E ADULTOS, 2007)

Ao argumentar em favor da implantação de coletivos de educado- 
Alves (1998) e Miguel (1996), em seus estudos sobre o tipo de contratação dos professores e o trabalho pedagógico, já indicavam que a existência do temporário ou substituto resulta da ausência de uma política educacional comprometida com a qualidade social da educaçáo e dos processos pedagógicos. A forma como vem sendo feita a contratação dos profissionais para a EJA traz prejuízos tanto para as relaçóes de trabalho quanto para a construção e continuidade de projetos pedagógicos, dada a alta rotatividade do grupo. A precarizaçáo do trabalho dos profissionais afeta-a como modalidade educativa, pois sua organização pedagógica fica fragilizada a cada ano e dificulta a consolidação do projeto político-pedagógico.

Depoimentos de professores evidenciam os principais fatores que os fizeram ingressar profissionalmente na EJA: a necessidade de um emprego, a proximidade do local de residência, o descontentamento com a escola atual e o desejo de realizar um trabalho diferenciado, como se evidencia nas falas de vários docentes:

Eu vim pra (N) em 2008 estava sem emprego e vi o concurso da prefeitura. Tinha vagas para o ensino de ciências no ensino regular e EJA. Como eu náo sabia do que se tratava eu fiz a seleção para os dois e passei nos dois. (Professor J)

Foi em 2001. A gente se inscrevia para as vagas e tinha lá Educação de Jovens e Adultos à noite. Eu não sabia de nada, absolutamente de nada. Vou arriscar pra saber o que é isso. Como era próximo da minha casa, eu arrisquei. (Professora K) [...] um pouco pela questáo da proposta trabalhar diferente, e um pouco pelo descontentamento de onde eu estava trabalhando. $\mathrm{Na}$ escola que eu estava trabalhando no regular, eu não via muita possibilidade de mudança na forma de trabalhar. (Professor U)

As afirmaçóes acima, de certo modo, expóem o distanciamento de reflexôes acerca da educação de jovens e adultos na formação inicial. Isso indica que tanto o Professor J quanto a Professora K, a exemplo de muitos outros, passaram a ter contato com as concepçóes, teorias e práticas da EJA quando já estavam atuando na modalidade. Nesse caso, a formação continuada, em certa medida, assume a função compensatória de suprir a 
defasagem de conhecimentos sobre a EJA, que deveria ser, prioritariamente, de competência da formaçáo inicial.

Paradoxalmente, diante dessa lacuna, a formação continuada tem representado uma alternativa importante para as redes de ensino. Em face dessa realidade, vale realçar o depoimento da Professora K, que atua desde 2001: "Operou-se uma modificação em mim, eu sinto isso, uma maturidade. Eu posso vislumbrar alguns caminhos. Comecei a me envolver mais. Comecei a ler coisas que não lia, a questionar mais." Ou o depoimento do Professor U: "A expectativa é contribuir com a inclusão de jovens e adultos de uma forma mais efetiva na vida social." Assim, se de um lado percebem-se acenos de disposiçóes que são muito desejáveis para compor uma condição política favorável ao ensino, importa reconhecer que será necessária, ainda, a constituição de condiçóes pedagógicas para concretizar tal propósito.

Embora se reconheçam avanços, nos últimos anos, na política educacional brasileira a EJA ainda sofre com uma concepção compensatória ou supletiva, emergencial e filantrópica, com professores pouco preparados para essa área de atuação, além de um afrouxamento na constituiçáo de uma infraestrutura político-pedagógica para o trabalho educativo.

\section{A formação continuada na percepção dos profissionais da EJA}

A formação dos professores para a EJA tem estado mais presente nos debates, eventos e pesquisas ${ }^{4}$ nos últimos anos. Pode-se dizer que a frequência dessa temática na pauta de encontros e até na formulação de políticas públicas está relacionada à reconfiguração dessa modalidade. Uma expressão desse reconhecimento emerge no argumento de Arroyo (2006, p. 17), para quem

a formação do educador e da educadora de jovens e adultos sempre foi um pouco pelas bordas, nas fronteiras onde estava acontecendo a EJA. Recentemente passa a ser reconhecida como uma habilitação ou como uma modalidade, como acontece em algumas faculdades de Educação. Nesse sentido, a formação 
dos educadores tem se inserido na problemática mais ampla da instituição da EJA como um campo pedagógico específico que, desse modo, requer a profissionalização dos seus agentes.

O mesmo autor chama a atenção para a ausência de parâmetros oficiais que delineiem o perfil desse educador e também de sua formação, o que se deve, em parte, pela própria indefinição da identidade da educação de pessoas jovens e adultas. Ao não ter sido institucionalizada no sistema de ensino, fez com que a formação do educador não tivesse um marco definido para a EJA. Arroyo não considera essa questão como um problema, pois entende que o perfil do educador de jovens e adultos, assim como a EJA, está em permanente construção; entretanto, alerta para a necessidade de uma formação mais específica para atender às peculiaridades da modalidade. Sua perspectiva é corroborada pelo Parecer CEB 11/2000, que apresenta as Diretrizes Curriculares Nacionais para a Educação de Jovens e Adultos, quando ressalta que "o preparo de um docente voltado para a EJA deve incluir, além das exigências formativas para todo e qualquer professor, aquelas relativas à complexidade diferencial desta modalidade de ensino." (BRASIL, 2000, p. 56)

Contudo, Soares (2008, p. 96) apontou dificuldades do campo quando analisou a trajetória profissional de professores, constatando que "o campo da EJA não construiu, ainda, o consenso de que possui especificidade que requer um profissional preparado para o exercício da função." Em sua compreensão, isso deriva das concepções da EJA, que variam, dependendo do lugar em que é oferecida. Outro aspecto destacado pelo pesquisador é que "mesmo que a formação inicial ofertada pela universidade seja considerada de qualidade, os egressos não necessariamente têm essa qualificação valorizada no momento da inserção profissional." (op.cit., p. 97)

A Resolução no 3/2010, que institui diretrizes operacionais para a Educação de Jovens e Adultos em seu Art. 10, coloca sob responsabilidade do Sistema Nacional Público de Formação de Professores o estabelecimento de políticas e ações específicas para a formação inicial e continuada de professores de Educação Básica de jovens e adultos, bem como para professores do ensino regular que atuam com adolescentes, cujas idades extrapolam a relação idade-série (BRASIL, 2010, p. 4). É assim que a for- 
mação continuada tem constituído uma alternativa importante para as redes de ensino, sobretudo diante da lacuna de conhecimentos sobre a EJA nas licenciaturas e a indefinição sobre o perfil do professor dessa modalidade. Para Gatti (2008, p. 58), isso "responde a uma situação particular nossa, pela precariedade em que se encontram os cursos de formaçáo de professores em nível de graduação."

Reconhecendo-se que essa é uma realidade subjacente a sua constituição, a formação continuada na EJA é também uma dimensão relevante na composição de uma política pública de educação de jovens e adultos, vinculada à formação inicial e às condições de trabalho, remuneração e carreira dos profissionais dessa modalidade educativa, na medida em que é concebida como

continuidade da formação profissional, proporcionando novas reflexôes sobre a ação profissional e novos meios para desenvolver e aprimorar o trabalho pedagógico; um processo de construção permanente do conhecimento e desenvolvimento profissional, a partir da formaçáo inicial e vista como uma proposta mais ampla, de hominização, na qual o homem integral, omnilateral, produzindo-se a si mesmo, também se produz em interação com o coletivo. (ASSOCIAÇÃO NACIONAL PELA FORMAÇÃO DOS PROFESSORES EM EDUCAÇÃO, 2000, p. 22-23)

Nessa compreensão, a atuação do professor é resultado de uma ampla articulação entre diversos processos implicados em sua trajetória de docência, incluindo espaços que vão desde a formação inicial e continuada até aqueles político-sociais e culturais não escolares.

$\mathrm{Na}$ RME a formação continuada acontece de duas maneiras: em cursos de curta duração centralizados e ofertados pela Secretaria Municipal e nos encontros semanais em cada núcleo. A contratação dos professores é de 30 horas semanais e, destas, 20 horas são para atuação com os estudantes; as demais horas integram as horas-atividade que são desenvolvidas coletivamente duas vezes por semana, no período vespertino. As horas-atividade são entendidas pelos profissionais como formação continuada, por corresponderem a tarefas de organização do trabalho pedagógico, avaliação dos estudantes, estudo de textos, entre outras. 
A inclusão da formação continuada na jornada de trabalho dos profissionais da EJA pode ser vista como um avanço se considerado que, com essa carga horária, os mesmos tendem a concentrar-se, exclusivamente, nessa modalidade. $\mathrm{O}$ modo como é compreendida a formação continuada, a partir da organização semanal do trabalho pedagógico, pode contribuir para minimizar as dificuldades em face da grande rotatividade anual de professores. Com isso, os coletivos dos núcleos tendem a assumir processo de formação continuada dos profissionais da EJA.

Os profissionais entrevistados reconhecem a necessidade da formação continuada para o desempenho do trabalho pedagógico na EJA, pois se ressentem da ausência desses conhecimentos na formação inicial. Contudo, há críticas: uma das professoras questiona o tipo de formação realizada por consultores; outra relata a repetição dos assuntos tratados, o que se deve à renovaçáo de professores a cada ano. Para esta última, o importante é discutir a prática que realizam, buscando respostas e saídas para suas dificuldades. Acredita que os próprios profissionais que atuam na RME podem desenvolver práticas formativas e que isso inclusive os valoriza.

Um destaque presente nos relatos é a necessidade de certa coerência entre o que é dito e o que é realizado na formação continuada, além de que, para os professores, o processo formativo deve levar em conta o 'como' realizar o que a proposta curricular propõe. A dinâmica da formação faz emergir elementos que corroboram a necessidade de uma relação muito profunda entre os seus objetos/processos e os sujeitos reais que ali se encontram. Senão, vejamos: o Professor J. expóe algo que apareceu com alguma frequência nos encontros dos coletivos observados, a saber, a ausência de preparo para atuar com o processo de letramento dos jovens e adultos e a ausência, nos cursos de licenciatura, das questóes didático-pedagógicas pertinentes à modalidade: "Eu tenho muitas dificuldades em trabalhar com esses alunos que não conseguem ler e entender o que leem, escrever. Eu me sinto, às vezes, como um professor que precisa alfabetizar, e a minha faculdade não me treinou."

Consideradas as dificuldades, bem como os alcances, evidenciamse fragilidades no plano da formação continuada proposta pela RME: o distanciamento entre o conteúdo da formação e a prática docente; a não focalização dos sujeitos das práticas; a não participação dos professores nas 
decisóes sobre os conteúdos da formação docente; a lógica formativa que, em geral, segue o modelo do uso de palestras, para um grupo que pode chegar a cem participantes, entre professores e coordenadores, dificultando o aprofundamento das questóes da prática educativa.

Arroyo (2006) destaca que a formação de educadores precisa levar em conta algo que integra os aspectos, esses antes realçados, das falas dos profissionais quanto à situação da modalidade, qual seja, de que está em foco a sua construção como política pública de responsabilidade e dever do Estado, incorporando as heranças acumuladas das experiências e histórias da educação de jovens e adultos. Desse modo, as especificidades da vida de jovens e adultos das camadas populares precisa se constituir no núcleo da formação. As particularidades da sua condição social, étnica, cultural e geográfica, ou seja, de jovens e adultos populares do campo e das periferias urbanas como ponto de referência para a construção da EJA e para a constituição do perfil do educador. (ARROYO, 2006)

Tendo os sujeitos jovens e adultos como centrais na formação, outras questôes podem ser agregadas, por exemplo, o domínio das teorias pedagógicas, podendo chegar até a se "inventar uma Pedagogia da vida adulta, da juventude." (op.cit., p.24) A história dos direitos humanos, aliada aos movimentos pelo direito à educação, é mais um aspecto sugerido por Arroyo (op.cit., p. 28), para quem "é impossível ser educador de jovens e adultos sem ter consciência dessa trajetória, dos vínculos entre EJA e luta por direitos." (id.ib.) O autor sugere a capacitação dos docentes no domínio dos 'conhecimentos vivos', que são os conhecimentos coletivos do trabalho, da história, da experiência, da cultura e da natureza que os jovens e adultos têm de "aprender a ressignificar e organizar à luz do conhecimento histórico.” (op.cit., p.31) Parece justo considerar que, nesse conjunto de elementos identificadores de uma estratégia política para a EJA, ressignificamos, aqui num sentido de ampliação, o que está nas falas dos profissionais educadores.

Assim, também em Barreto (2006) buscamos aspectos práticos que orientam as 'aprendizagens' sobre a formação continuada, dos quais destacamos:

Sem se transformar num processo permanente, a formação pode muito pouco; [...] É equivocada a crença de que é necessário 
aprender primeiro e fazer depois. Aprendemos fazendo se pensarmos sobre o que estamos fazendo [...] A metodologia usada na formação precisa necessariamente ser a mesma que está sendo proposta aos educadores. [...] A formaçáo permanente, que se constitui como espaço privilegiado de reflexão da ação dos educadores tendo em vista a melhoria dessa ação, é um processo exigente. [...] É preciso obter a cumplicidade do educador; é preciso contar com formadores que além de terem competência no fazer pedagógico, sejam competentes na condução e estimulação do grupo; o trabalho de formação demanda tempo; a formação exige espaços e horários bem definidos. (BARRETO, 2006, p. 100)

Tanto os aspectos filosóficos apontados por Arroyo quanto os práticos apresentados por Barreto remetem a necessidades apontadas nas problematizações e desafios inscritos nas falas dos sujeitos desta pesquisa. Contudo, destaca-se um aspecto decisivo para a constituição da capacidade político-pedagógica, qual seja: a importância de os professores participarem do planejamento e da definição das temáticas a serem abordadas no processo formativo, o que somente pode ocorrer em processos em que as práticas - aqui em um sentido amplo - da EJA se constituam em espaço formativo no qual os professores desenvolvem atividades de pesquisa, a partir de problemáticas que possibilitem refletir sobre as práticas que realizam.

\section{Algumas consideraçóes}

O objetivo deste texto foi discutir a formação continuada oferecida aos profissionais que atuam na EJA em suas interfaces com os processos de ingresso e de constituição da docência dos professores dessa modalidade educativa, tomando para estudo empírico o caso de uma Rede de Municipal de Ensino. Preservadas as particularidades da RME em foco, destaca-se que a concepção de provisoriedade dos gestores públicos sobre essa modalidade educativa dificulta que o poder público assuma a educação como direito para jovens e adultos, o que demonstra a baixa institucionalização da EJA nos sistemas de Educação Básica. 
Outros fatores foram identificados durante o estudo realizado, entre eles a precarização das condiçôes de trabalho dos profissionais que, na sua maioria, são admitidos em caráter temporário. A forma de contratação dos profissionais para a EJA, do modo como se realiza, traz prejuízos tanto para as relaçóes de trabalho quanto para a construção e continuidade de projetos pedagógicos, dada a alta rotatividade do grupo. Os motivos que mobilizaram os profissionais entrevistados a ingressarem na EJA estão vinculados à necessidade de um emprego, à proximidade do local de residência, ao descontentamento com o ensino chamado 'regular' e até ao desejo de realizar um trabalho diferenciado.

Os professores também reconhecem a importância da formação continuada como espaço de reflexão sobre as suas práticas, pois admitem um certo desconhecimento da EJA. Esse dado revela que grande parte das licenciaturas não têm contemplado as especificidades do fazer docente na EJA. Com isso, o contato com as concepçôes, teorias e práticas dá-se quando já estão atuando no cotidiano dessa modalidade. Por outro lado, é preciso admitir que a formação continuada tem representado uma alternativa importante para as redes de ensino, diante da ausência nos cursos de formação inicial.

Ficou evidente, no estudo realizado, as desvantagens com que a EJA desvantagens e a pouca valorização dessa modalidade, embora não explícitas, têm relação direta com seu público de jovens e adultos e as particularidades de sua "condição social, étnica, racial, cultural e espacial (de jovens e adultos populares do campo, das vilas, favelas)." (ARROYO, 2006, p. 23)

A reconfiguraçáo do campo da EJA a partir dos seus sujeitos impóe grande complexidade, fazendo emergir a necessidade de se discutir a especificidade da docência para essa modalidade, implicando colocar em pauta quem sáo os professores e professoras que nela atuam, como nela ingressam, que processos formativos vivenciam e o que pensam sobre eles. Sabe-se que fatores diversos podem interferir nas práticas dos professores, mas eles nem sempre estão subordinados à ausência de formação, ou ao seu caráter e dinâmica, como no caso dos tensionamentos entre professores e gestores, a situação funcional dos professores, o desprestígio de atuar em EJA, os baixos salários, o caráter supletivo da modalidade, entre outros. 
Assim, a formação continuada de professores continua sendo um aspecto tanto fundamental quanto desafiador na composiçáo da oferta da política educacional para jovens e adultos.

\section{Notas}

1 Os profissionais entrevistados serão aqui identificados pelas letras: M (coordenadora) e J, K, W e U (professores).

2 Artes Cênicas, Música, Ciências, Espanhol, Geografia, História, Inglês, Matemática e Português.

3 Laffin e Gaya (2013) informam que em Santa Catarina, de 75 cursos analisados, em 21 instituições, somente 13 ofertam disciplinas ou estudos sobre EJA.

4 Nos espaços acadêmicos, aparece de modo mais sistemático, a partir de 1998, com a criação de um grupo no âmbito da Associação Nacional de Pós-Graduação e Pesquisa em Educação (ANPEd).

\section{Referências}

ALVES, Sônia. Professores efetivos, professores substitutos: caminhos de persistência e rendição norteados pelo tipo de contratação. Dissertação (Mestrado em Psicologia) Universidade Federal de Santa Catarina, Florianópolis, 1998.

ARROYO, Miguel Gonzáles. Formar educadoras e educadores de jovens e adultos. In: SOARES, L. Formação de educadores de jovens e adultos. Belo Horizonte: Autêntica; SECAD-MEC; UNESCO, 2006.

\section{ASSOCIAÇÃO NACIONAL PELA FORMAÇÃO DOS PROFESSORES EM EDUCAÇẤO (ANFOPE). Documento Final X Encontro Nacional, Brasília, 2000.}

BARRETO, V. Formação permanente ou continuada. In: SOARES, Leôncio. Formação de Educadores de jovens e adultos. Belo Horizonte: Autêntica; SECADMEC;UNESCO, 2006.

BRASIL. Ministério da Educação. Conselho Nacional de Educação. Parecer CNE/ CEB 11/2000. Diretrizes Curriculares Nacionais para a Educação de Jovens e Adultos. Disponível em: http://portal.mec.gov.br/cne/arquivos/pdf/PCB11_2000.pdf. Acesso em: 05 nov. 2018.

BRASIL. Ministério da Educação. Conselho Nacional de Educação. Resolução no 3, de 15 de junho de. 2010. Institui Diretrizes Operacionais para a Educação de Jovens e Adultos nos aspectos relativos à duração dos cursos e idade mínima para ingresso nos cursos de EJA; idade mínima e certificação nos exames de EJA; e Educação de Jovens e Adultos desenvolvida por meio da Educação a Distância. Disponível em: <http://portal. mec.gov.br/index.php?option=com_docman\&view=download \&alias=5642-rceb00310\&category_slug=junho-2010-pdf\&Itemid=30192 >. Acesso em: 05 nov. 2018. 
DI PIERRO, Maria Clara. Um balanço da evolução recente da educação de jovens e adultos no Brasil. In: UNESCO. (org.) Construção coletiva: contribuições à educação de jovens e adultos. Brasília: UNESCO, MEC, RAAAB, 2005, p. 17-30.

DINIZ-PEREIRA, Júlio. Formação continuada de professores. In: OLIVEIRA, Dalila Andrade et al (Orgs.). Dicionário: trabalho, profissão e condição docente. Belo Horizonte, UFMG: Gestrado, 2010. CD-ROM.

GATTI, Bernadete Angelina. Análise das políticas públicas para formação continuada no Brasil, na última década. Revista Brasileira de Educação, Rio de Janeiro, v. 13, n. 37, jan./abr., p.57-70, 2008.

LAFFIN, Maria Hermínia Lage Fernandes; GAYA, Sidneya Magaly. Elementos constitutivos no campo da educação de jovens e adultos na formaçáo inicial docente em cursos de pedagogia nos documentos analisados na pesquisa. Revista Lugares de Educação, Bananeiras/PB, v. 3, n. 6, p. 38-57, jul./dez. 2013.

MACHADO, Maria Margarida. Processos de formação de educadores de jovens e adultos: os desafios políticos e pedagógicos da formação de educadores de EJA no Brasil. IN: DALBEN, Angela Imaculada et. al (Org.). Convergências e tensóes no campo da formação e do trabalho docente: educação de jovens e adultos. Belo Horizonte: Autêntica, abr. 2010. p 100-121.

MARIN, Aída Junqueira. Precarização do trabalho docente. IN: OLIVEIRA, Dalila Andrade et al. (Org.). Dicionário: trabalho, profissão e condição docente. Belo Horizonte, UFMG: Gestrado, 2010. CD-ROM.

MIGUEL, Denise Soares. O trabalho temporário no Magistério Público Estadual de Santa Catarina. 181 f. Dissertação (Mestrado em Educação) - Universidade Federal de Santa Catarina. Florianópolis, 1996.

SACRISTÁN, José Gimeno. O currículo: uma reflexão sobre a prática. Tradução de Ernani F da Rosa. 3. ed. Porto Alegre: Artmed, 1998.

SEMINÁRIO NACIONAL DE FORMAÇÃO DE EDUCADORES DE JOVENS E ADULTOS. Consideraçóes da Plenária Final 30 de maio a 02 de junho - Goiânia/GO (Versão Preliminar). 2007.

SOARES, Leôncio. O educador de jovens e adultos e sua formação. Educação em Revista, Belo Horizonte, n. 47, p. 83-100, jun. 2008.

Recebido em 30 mai. 20I8 / Aprovado em I5 out. 2018

\section{Para referenciar este texto:}

PASSOS, J. C. Professores na Educação de Jovens e Adultos: inserção, precarização e formação continuada. EccoS - Revista Científica, São Paulo, n. 47, p. 273-288. set/ dez. 2018. Disponível em: <https://doi.org/10.5585/EccoS.n47.5887>. 